\title{
Plasma Metabolomic Changes in Mice With Time-restricted Feeding-attenuated Spontaneous Metastasis of Lewis Lung Carcinoma
}

\author{
LIN YAN, BRET M. RUST and MATTHEW J. PICKLO \\ U.S. Department of Agriculture, Agricultural Research Service, \\ Grand Forks Human Nutrition Research Center, Grand Forks, ND, U.S.A.
}

\begin{abstract}
Background/Aim: Time-restricted feeding (TRF) during the dark phase of the day restores metabolic homeostasis in mice. Materials and Methods: We performed untargeted metabolomic analysis on plasma from mice subjected to TRF that attenuates high-fat diet-enhanced spontaneous metastasis of Lewis lung carcinoma (LLC). Results: Twenty-four of 152 identified metabolites differed among the four dietary groups (non-LLC-bearing mice fed the AIN93G diet and LLC-bearing mice fed the AIN93G, the highfat diet (HFD), or TRF of the HFD). Component 1 of sparse partial least squares-discriminant analysis showed a clear separation between non-LLC-bearing and LLC-bearing mice. Major metabolites responsible for the changes were elevations in $\alpha$-tocopherol, docosahexaenoic acid, cholesterol, dihydrocholestrol, isoleucine, leucine, and phenylalanine and decreases in lactic acid and pyruvic acid in LLC-bearing mice particularly those fed the HFD. Time-restricted feeding shifted the metabolic profile of LLC-bearing mice towards that of non-LLC-bearing controls. Conclusion: Time-restricted feeding improves metabolic profile of LLC-bearing mice.
\end{abstract}

The maintenance of metabolic homeostasis is fundamental for human health and wellbeing; its disruption is a common feature of chronic disorders and diseases. Obesity is a disorder of excessive body fat with associated metabolic complications. In contrast, cancer is a wasting disease accompanied by deprivation of energy and nutrients as the disease progresses. Often, obese cancer patients experience poor prognosis, early

This article is freely accessible online.

Correspondence to: Lin Yan, Ph.D., USDA, ARS, Grand Forks Human Nutrition Research Center, 2420 2nd Avenue North, Grand Forks, ND 58203, U.S.A. Tel: +1 7017958499, Fax: +1 7017958220, e-mail: Lin.Yan@ars.usda.gov

Key Words: Metabolomics, plasma, diet, time-restricted feeding, Lewis lung carcinoma, mice. recurrence, and a shorter disease-free interval than patients who are normal in body weight $(1,2)$. Consistent with human studies, aggressive primary tumorigenesis $(3,4)$ and metastasis $(4,5)$ occur in obese rodents fed high-fat diets (HFD), that usually provide $45 \%$ or a higher amount of energy from dietary fat.

Circadian clocks that exist in all biological systems cycle approximately every 24 hours and control the daily rhythms of metabolic homeostasis. Both obesity and cancer disrupt circadian rhythms and lead to metabolic dysfunction. For example, intake of a HFD disrupts the diurnal rhythm of energy expenditure (6) and circadian gene expression in mice (7). In addition, experimentally induced tumorigenesis disrupts rhythmic expression of circadian genes of the hosts $(8,9)$. Time-restricted feeding (TRF) is an effective tool to restore the daily pattern of feeding and fasting and reinforces the circadian rhythm of energy metabolism in rodents. Time-restricted feeding of a HFD allows mice access to food in certain hours of the active phase of the day (the dark phase for nocturnal rodents) and restores diurnal oscillations of energy metabolism (6) and circadian gene expression (7). Furthermore, TRF reduces the HFD-enhanced primary tumorigenesis (10) and metastasis (11) in mouse models of human cancer.

The deprivation of energy reserves due to an inefficiency in energy production through aerobic glycolysis is a common feature of cancer $(12,13)$. We recently reported that TRF (12 hours during the dark phase) attenuates pulmonary metastasis of Lewis lung carcinoma (LLC), improves insulin sensitivity, and alters plasma concentrations of biomarkers related to energy metabolism (e.g. leptin and adiponectin) in mice fed a HFD (11). Lewis lung carcinoma is an aggressive model of spontaneous metastasis; it spreads to the lungs and forms metastases detectable within two weeks after the establishment of a primary tumor from subcutaneously injected LLC cells $(11,14)$. Our findings indicate that TRF may affect plasma metabolites, especially those involved in energy homeostasis during malignant progression. A greater understanding of the metabolomic responses in plasma would allow for improved 
assessment of TRF as a potential intervention to reduce metastatic growth. The objective of the current study was to identify TRF-induced metabolic fingerprints in plasma from mice with HFD-enhanced pulmonary metastasis. To achieve this, metabolomic analysis was performed on plasma from mice subjected to TRF that attenuates HFD-enhanced pulmonary metastasis of LLC (11).

\section{Materials and Methods}

Animals and diets. Three to four-week-old male C57BL/6 mice (Envigo, Madison, WI, USA) were housed in a pathogen-free room with a 12:12-hour light/dark cycle and a temperature of $22 \pm 1^{\circ} \mathrm{C}$. The standard AIN93G diet providing $16 \%$ of energy from soybean oil (15) and a modified AIN93G diet (11) providing 45\% of energy from soybean oil (hereafter referred to as the high-fat diet, HFD) were used in this study.

Experimental design. The Institutional Animal Care and Use Committee of the Grand Forks Human Nutrition Research Center approved this study (Project No. YAN032). The study procedures followed the Guide for the Care and Use of Laboratory Animals by the National Institutes of Health (16).

The study design has been previously reported (11). Briefly, after acclimation to the AIN93G diet for one week, mice were assigned into two groups and fed the AIN93G diet $(n=28)$ or the HFD $(n=56)$. Mice were housed individually. Three weeks later, mice fed the HFD were further assigned into two groups of 28 each. One group remained on the same feeding regimen, while the other had their diets restricted to the dark phase for 12 hours between Zeitgeber times (ZT) 12 and 24 (hereafter referred to as timerestricted feeding, TRF). Mice of the TRF group were transferred to cages containing water only at ZT 0 (light on) and returned to their home cages containing both diet and water at ZT 12 (light off) daily. Mice with unrestricted access to their diets were transferred between cages containing both diet and water daily at ZT 0 and 12 . The duration of the restricted feeding was 10 weeks (11).

The induction of lung metastasis has been described previously (11). Seven weeks after the TRF, mice were injected subcutaneously with LLC cells into the lower dorsal region. The resulting subcutaneous tumor was resected when it was approximately $1 \mathrm{~cm}$ in diameter. Following surgery, mice continued their respective feeding regimen for an additional 10 days (11). Mice fed the AIN93G diet but not injected with LLC cells served as non-LLCbearing controls. At the termination, lungs were harvested to examine the extent of metastasis. Plasma was collected for metabolomic analysis.

Plasma metabolomics. Metabolomic analysis $(17,18)$ was performed at the West Coast Metabolomics Center (University of CaliforniaDavis Genomic Center, Davis, CA, USA). Plasma samples were extracted and derivatized by silylation methyloximation and analyzed by gas chromatography time-of-flight mass spectrometry (GC-TOFMS) for untargeted metabolomics of primary metabolism. Obtained data were processed at the West Coast Metabolomics Center by using the BinBase database (19). Metabolite quantifier ion peak heights were normalized to the sum intensities of all known compounds and used for statistical analyses.
Statistical analysis. Obtained data were analyzed by using the MetaboAnalyst software (version 3.0, McGill University, Sainte Anne de Bellevue, Quebec, Canada) (20,21). Data were normalized by Pareto scaling method and analyzed by sparse partial least squares-discriminant analysis (sPLS-DA) (20, 21). One-way analysis of variance (ANOVA) and Tukey's test were performed to compare differences among the four dietary groups. A false discovery rate (FDR) of 0.05 was applied; the FDR-corrected $p$ values were reported (20). Results from the treatment groups were converted to fold changes in comparison to the non-LLC-bearing control group and are presented as means \pm standard error of the mean (SEM).

\section{Results}

We identified 152 metabolites from 475 discrete signals detected in the plasma by using GC-TOF-MS. Hierarchical clustering and heatmapping of the 24 metabolites that differed significantly among the four groups are shown in Figure 1. The relative values for the different metabolites, compared to plasma values from non-LLC-bearing control mice, are shown in Table I.

Clustered heatmapping separated the plasma metabolites into four general categories, 1) those elevated in non-LLC-bearing mice fed the standard AIN93G diet, 2) those elevated in AIN93G-fed mice with and without LLC, and 3) those elevated in LLC-bearing mice with TRF or 4) fed the HFD (Figure 1).

As a complementary method, sPLS-DA was used to visualize group separations and individual sample variability and to identify the metabolites underlying these separations (Figure 2).

Component 1 separated the dietary groups into three categories 1) non-LLC-bearing mice fed the AIN93G diet, 2) LLC-bearing mice fed the AING93G or with TRF, and 3) LLC-bearing mice fed the HFD (Figure 2A). The loadings plot for component 1 identified $\alpha$-tocopherol, aromatic and branched chain amino acids phenylalanine, isoleucine, and leucine, long chain polyunsaturated fatty acids, cholesterol metabolites, and the glycolytic metabolites pyruvic acid and lactic acid as major determinants of separation (Figure 2C).

Component 2 separated dietary groups based upon intake of the HFD (unrestricted feeding or TRF) vs. the AIN93G diet (with or without LLC metastasis) (Figure 2A). The loadings plot for component 2 identified the glucose metabolite 1,5-anhydroglucitol, the fatty acids myristic acid (14:0), palmitoleic acid (16:1n-7), palmitic acid (16:0), and lauric acid (12:0), and amino acids aspartic acid, glutamine, and cystine as major determinants of separation (Figure 2D).

Component 3, unlike the other axes, separated the TRF group from the other three groups (Figure 2B). The major determinants of separation were linoleic acid $(18: 2 n-6), 3-$ hydroxybutyric acid (also known as $\beta$-hydroxybutyrate), 4hydroxybenzoate, and the odd chain fatty acid margaric acid (17:0) (Figure 2E). 


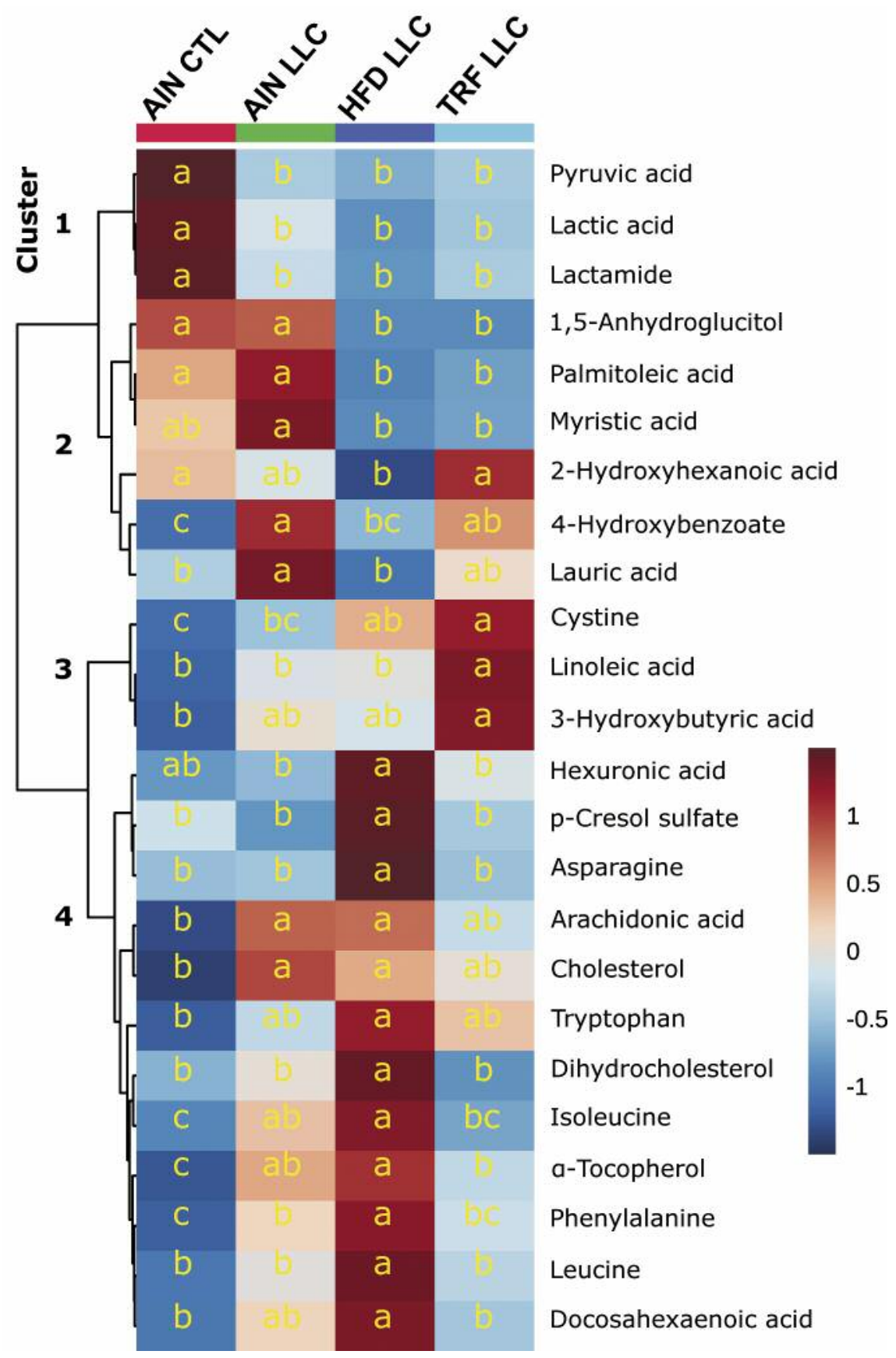

Figure 1. Hierarchical clustering heatmap analysis of the top 24 plasma metabolites that differ among the four dietary groups. AIN Ctl (red): nonLewis lung carcinoma (LLC) bearing mice fed the AIN93G diet; AIN LLC (green): LLC-bearing mice fed the AIN93G diet; HFD LLC (blue): LLCbaring mice fed the HFD; TRF LLC (cyan): LLC-bearing mice with time-restricted feeding of the HFD. Different letters in the cells in each row indicate significance at $p \leq 0.05$ ( $n=8$ per group).

\section{Discussion}

Cancer progression deprives nutrients from the host to support the rapid growth of the malignancy. Lewis lung carcinoma is a model of spontaneous metastasis (22); its aggressiveness is enhanced by the intake of high-fat diets $(11,14)$. However, TRF abates the enhanced LLC metastasis (11). The objective of the current study was to identify TRF-induced metabolic fingerprints in plasma from mice with HFD-enhanced lung metastasis through a combination of non-targeted 
Table I. Identified metabolites that differ between non-Lewis lung carcinoma (LLC) bearing mice fed the AIN93G diet (AIN Ctl) and LLC-bearing mice fed the AIN93G diet (AIN LLC), the high-fat diet (HFD LLC), and time-restricted feeding of the HFD (TRF LLC). Values (mean $\pm S E M)$ with different letters are significant at $p<0.05$ ( $n=8$ per group).

\begin{tabular}{|c|c|c|c|c|c|}
\hline Metabolic pathway & Metabolite & AIN Ctl & AIN LLC & HFD LLC & TRF LLC \\
\hline Vitamin & $\alpha$-Tocopherol & $1.00 \pm 0.33 \mathrm{c}$ & $5.29 \pm 0.74 \mathrm{ab}$ & $6.80 \pm 0.73 \mathrm{a}$ & $3.43 \pm 0.46 \mathrm{~b}$ \\
\hline \multirow[t]{7}{*}{ Proteins } & Asparagine & $1.00 \pm 0.07 \mathrm{~b}$ & $1.01 \pm 0.10 \mathrm{~b}$ & $1.44 \pm 0.14 \mathrm{a}$ & $1.00 \pm 0.07 \mathrm{~b}$ \\
\hline & Cystine & $1.00 \pm 0.14 \mathrm{c}$ & $1.26 \pm 0.18 \mathrm{bc}$ & $1.65 \pm 0.14 \mathrm{ab}$ & $1.99 \pm 0.18 \mathrm{a}$ \\
\hline & Leucine & $1.00 \pm 0.11 \mathrm{~b}$ & $1.24 \pm 0.06 \mathrm{~b}$ & $1.58 \pm 0.06 \mathrm{a}$ & $1.17 \pm 0.08 \mathrm{~b}$ \\
\hline & Isoleucine & $1.00 \pm 0.04 \mathrm{c}$ & $1.18 \pm 0.05 \mathrm{ab}$ & $1.31 \pm 0.05 \mathrm{a}$ & $1.03 \pm 0.03 \mathrm{bc}$ \\
\hline & Phenylalanine & $1.00 \pm 0.03 \mathrm{c}$ & $1.24 \pm 0.06 \mathrm{~b}$ & $1.41 \pm 0.04 \mathrm{a}$ & $1.17 \pm 0.04 \mathrm{bc}$ \\
\hline & Tryptophan & $1.00 \pm 0.07 \mathrm{~b}$ & $1.20 \pm 0.14 \mathrm{ab}$ & $1.52 \pm 0.09 \mathrm{a}$ & $1.33 \pm 0.07 \mathrm{ab}$ \\
\hline & p-Cresol sulfate & $1.00 \pm 0.06 \mathrm{~b}$ & $1.07 \pm 0.06 \mathrm{~b}$ & $1.70 \pm 0.23 \mathrm{a}$ & $1.22 \pm 0.06 \mathrm{~b}$ \\
\hline \multirow[t]{6}{*}{ Sugars } & Pyruvic acid & $1.00 \pm 0.07 \mathrm{a}$ & $0.51 \pm 0.04 \mathrm{~b}$ & $0.46 \pm 0.08 \mathrm{~b}$ & $0.51 \pm 0.08 \mathrm{~b}$ \\
\hline & Lactic acid & $1.00 \pm 0.14 \mathrm{a}$ & $0.61 \pm 0.06 \mathrm{~b}$ & $0.43 \pm 0.06 \mathrm{~b}$ & $0.52 \pm 0.10 \mathrm{~b}$ \\
\hline & Lactamide & $1.00 \pm 0.09 \mathrm{a}$ & $0.69 \pm 0.04 \mathrm{~b}$ & $0.59 \pm 0.07 \mathrm{~b}$ & $0.66 \pm 0.10 \mathrm{~b}$ \\
\hline & 1,5-Anhydroglucitol & $1.00 \pm 0.06 \mathrm{a}$ & $0.98 \pm 0.07 \mathrm{a}$ & $0.59 \pm 0.02 \mathrm{~b}$ & $0.58 \pm 0.03 \mathrm{~b}$ \\
\hline & 3-Hydroxybutyric acid & $1.00 \pm 0.23 \mathrm{~b}$ & $3.49 \pm 1.00 \mathrm{ab}$ & $3.11 \pm 0.32 \mathrm{ab}$ & $5.92 \pm 1.06 \mathrm{a}$ \\
\hline & Hexuronic acid & $1.00 \pm 0.11 \mathrm{ab}$ & $0.88 \pm 0.09 \mathrm{~b}$ & $1.33 \pm 0.06 \mathrm{a}$ & $0.95 \pm 0.08 \mathrm{~b}$ \\
\hline \multirow[t]{10}{*}{ Lipids } & Cholesterol & $1.00 \pm 0.04 \mathrm{~b}$ & $1.48 \pm 0.09 \mathrm{a}$ & $1.38 \pm 0.10 \mathrm{a}$ & $1.29 \pm 0.07 \mathrm{ab}$ \\
\hline & Dihydrocholesterol & $1.00 \pm 0.07 \mathrm{~b}$ & $1.26 \pm 0.08 \mathrm{~b}$ & $1.83 \pm 0.16 \mathrm{a}$ & $0.92 \pm 0.15 \mathrm{~b}$ \\
\hline & Arachidonic acid & $1.00 \pm 0.11 \mathrm{~b}$ & $2.00 \pm 0.21 \mathrm{a}$ & $1.98 \pm 0.19 \mathrm{a}$ & $1.50 \pm 0.11 \mathrm{ab}$ \\
\hline & Linoleic acid & $1.00 \pm 0.08 \mathrm{~b}$ & $1.74 \pm 0.17 \mathrm{~b}$ & $1.76 \pm 0.17 b$ & $2.68 \pm 0.24 \mathrm{a}$ \\
\hline & Docosahexaenoic acid & $1.00 \pm 0.09 \mathrm{~b}$ & $1.37 \pm 0.09 \mathrm{ab}$ & $1.71 \pm 0.19 \mathrm{a}$ & $1.17 \pm 0.15 b$ \\
\hline & Palmitoleic acid & $1.00 \pm 0.10 \mathrm{a}$ & $1.33 \pm 0.26 \mathrm{a}$ & $0.36 \pm 0.03 \mathrm{~b}$ & $0.45 \pm 0.04 \mathrm{~b}$ \\
\hline & Myristic acid & $1.00 \pm 0.06 \mathrm{ab}$ & $1.33 \pm 0.19 \mathrm{a}$ & $0.63 \pm 0.03 \mathrm{~b}$ & $0.67 \pm 0.03 \mathrm{~b}$ \\
\hline & Lauric acid & $1.00 \pm 0.06 \mathrm{~b}$ & $1.44 \pm 0.09 \mathrm{a}$ & $0.84 \pm 0.06 \mathrm{~b}$ & $1.13 \pm 0.17 \mathrm{ab}$ \\
\hline & 2-Hydroxyhexanoic acid & $1.00 \pm 0.04 \mathrm{a}$ & $0.93 \pm 0.06 \mathrm{ab}$ & $0.74 \pm 0.04 \mathrm{~b}$ & $1.12 \pm 0.08 \mathrm{a}$ \\
\hline & 4-hydroxybenzoate & $1.00 \pm 0.09 \mathrm{c}$ & $1.98 \pm 0.25 \mathrm{a}$ & $1.22 \pm 0.13 \mathrm{bc}$ & $1.74 \pm 0.15 \mathrm{ab}$ \\
\hline
\end{tabular}

metabolomics, hierarchical clustering with heatmapping, and multivariate analysis (sPLS-DA) $(20,21)$. Non-targeted analysis of the plasma metabolome identified a total of 152 metabolites, of which 24 differed among the four dietary groups. These findings indicate that LLC metastasis modifies selective metabolic pathways and supports the notion that metabolomic fingerprints in the plasma may be useful for identifying changes in the metastatic phenotype.

Multivariate analysis and clustered heatmapping clearly showed that plasma metabolomic profiles segregated the dietary groups. Component 1 of the sPLS-DA showed the separation of non-LLC-bearing mice from LLC-bearing mice. It demonstrated that along this $\mathrm{x}$-axis the AIN93G diet created a metabolomic profile closer to that of the HFD in LLC-bearing mice and that, most importantly, TRF shifted the metabolomic profile of LLC-bearing mice closer to that of non-LLC-bearing controls. This is the case, except for a few exceptions, for most of the metabolites shown in the loadings plot for component 1 . This shift is a strong evidence that TRF improves the metabolism of LLC-bearing mice. This improvement may be responsible, at least partly, for the TRF mitigation of LLC metastasis.
$\alpha$-Tocopherol is a major determinant of separation of the dietary groups. Levels of $\alpha$-tocopherol were higher in the plasma of LLC-bearing mice, particularly those fed the HFD; they were lower in TRF mice and did not differ from those in AIN93G-fed LLC-bearing mice. It has been shown that serum concentrations of $\alpha$-tocopherol are inversely associated with breast cancer risk (23) and that $\alpha$-tocopherol is antitumorigenic in mouse models of breast cancer (24). However, it is also possible that elevated $\alpha$-tocopherol may be a means by which cancer cells increase defense against the host's immune system. For example, metabolic profiling of ovarian cancer showed an increase in tocopherols compared to normal ovarian tissues (25). The elevation in $\alpha$-tocopherol may be through either an increase in uptake or a lack of clearance (26). The decrease in $\alpha$-tocopherol by TRF suggests that TRF may modify these metabolic processes. Subsequent studies are needed to determine the mechanisms by which LLC metastasis increases $\alpha$-tocopherol in the plasma.

The metastasis of LLC disrupted protein metabolism. An elevation in amino acids in the plasma, including phenylalanine and branched chain amino acids leucine and isoleucine, occurred in LLC-bearing mice particularly those fed the HFD. 

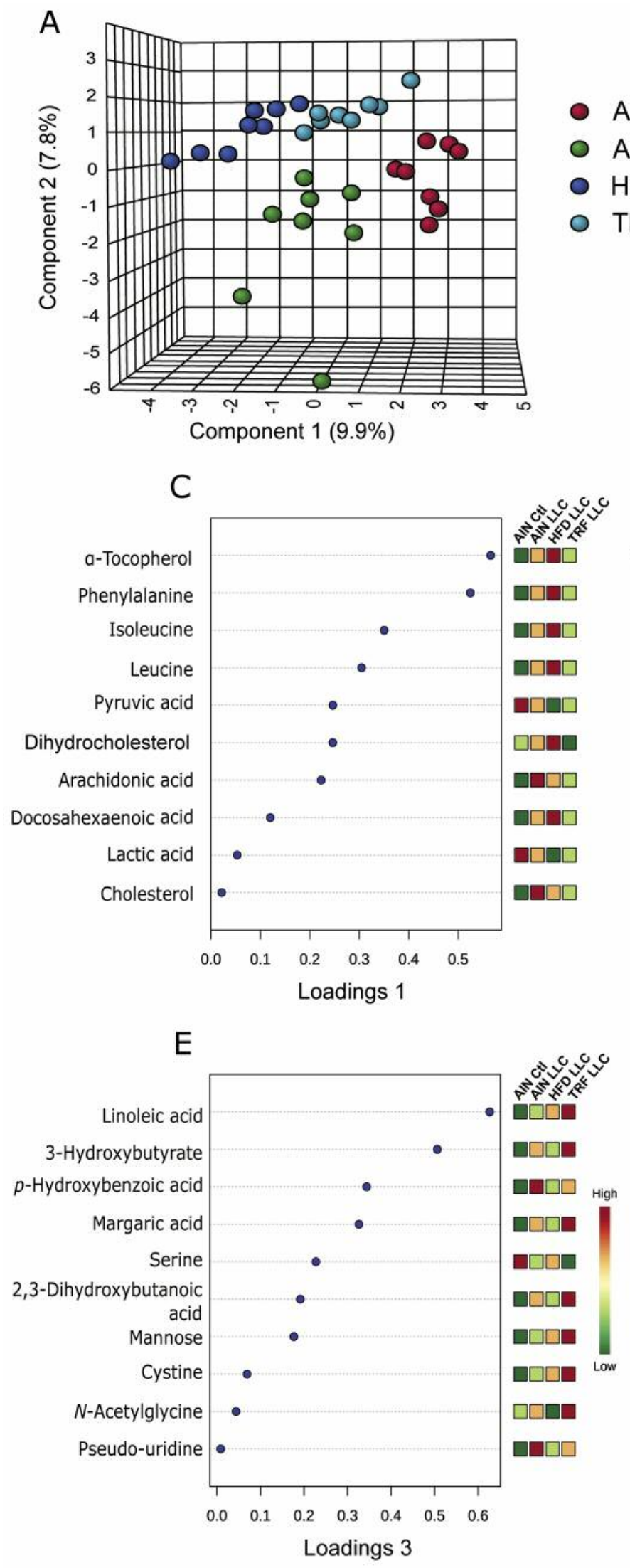

B

AIN CtI

AIN LLC

HFD LLC

TRF LLC

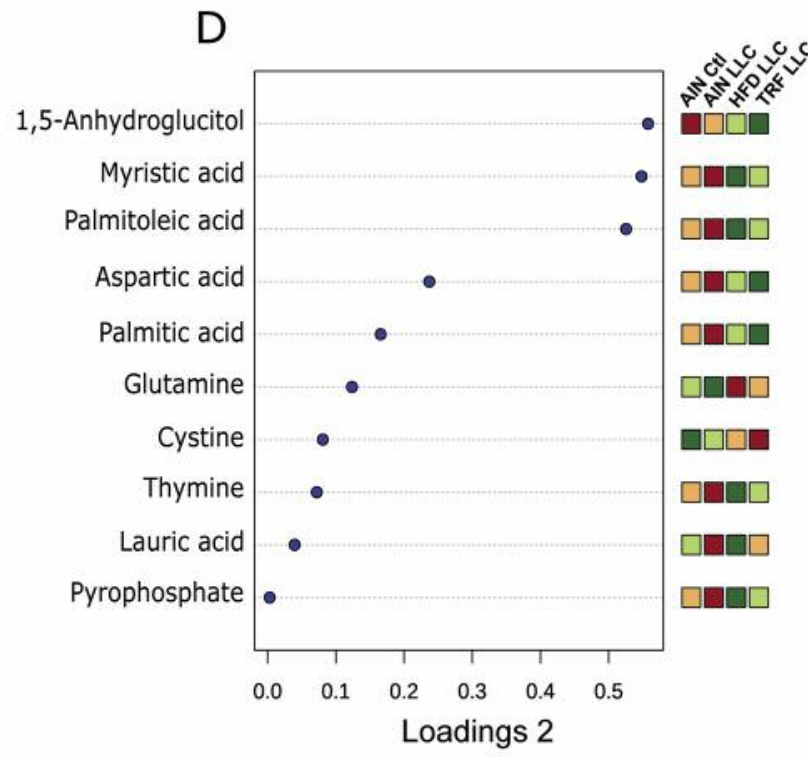

Figure 2. Sparse partial least square-discriminant analysissynchronized three-dimensional plots of the four dietary groups ( $A$ and $B$ ) and loading plots of 10 metabolites that are most influential in treatment separation among the four groups for components 1,2 , and $3(C, D$, and E). A: Components 1 vs. 2; B: Components 2 vs. 3. AIN Ctl (red): non-Lewis lung carcinoma ( $L L C$ ) bearing mice fed the AIN93G diet; AIN LLC (green): LLCbearing mice fed the AIN93G diet; HFD LLC (blue): LLC-baring mice fed the HFD; TRF LLC (cyan): LLC-bearing mice with timerestricted feeding of the $H F D$ ( $n=8$ per group). 
This elevation indicates an increase in host protein breakdown or a decrease in host protein synthesis that may provide the needed amino acids for the metastatic growth. This notion is supported by the elevation in p-cresol sulfate, a downstream metabolite of phenylalanine metabolism, in HFD-fed mice. It is further supported by the reports that elevated amino acids including both phenylalanine and branched chain amino acids occur in bladder cancer (27) and in the plasma from both human patients and mouse models of pancreatic ductal adenocarcinoma (28) and that this elevation is a result of increased muscle protein turnover (28). In the current study, TRF lowered amino acids (phenylalanine, leucine, isoleucine, and asparagine) and p-cresol sulfate in the plasma compared to the HFD, suggesting that TRF may attenuate the disrupted protein metabolism induced by LLC.

The current study showed that LLC-bearing mice may have a down-regulated glycolysis, evidenced by the lower levels of lactic acid, lactamide (a lactic acid derivative), and pyruvic acid in the plasma. This is supported by the aforementioned elevation in amino acids in LLC-bearing mice, as elevated amino acids in the plasma are a characteristic of impaired glucose metabolism (29). It is also supported by the lower concentrations of 1,5-anhydroglucitol in HFD-fed mice. 1,5-Anhydroglucitol is a marker of glycemic control; its blood level is inversely correlated with blood glucose (30). In fact, the HFD-fed mice have elevated glucose in the plasma (11). Our findings differ from human studies where lung cancer patients exhibited elevated blood levels of lactic acid when compared to healthy controls (31, 32 ) and from in vitro studies where neoplastic cells produce high amounts of lactic acid (33). The elevation in lactic acid in cancer attributes to the Warburg Effect in which cancer cells predominantly produce their energy through a high rate of glycolysis followed by lactic acid production $(12,34)$. The difference from the current study may be because we studied the early stage of metastasis, in which metastatic modules were analyzed in $\mathrm{mm}^{2}$ in size (11). This certainly differs from studies with large tumor burden in terms of wasting and cancer metabolism $(31,32)$. Furthermore, this downregulation of glycolysis in the presence of LLC seemed to be strong; TRF did not affect this shift in metabolism.

The finding that TRF increased 3-hydroxybutyric acid in the plasma is consistent with the reports on fasting in mice (35) and caloric restriction in rats (36). 3-Hydroxybutyric acid, a ketone body, is generated from excessive acetyl-CoA production resulting from fatty acid $\beta$-oxidation. Its elevation indicates that ketone bodies are sources of energy when glycolysis does not function during the restricted feeding.

The elevation in cholesterol and its derivative dihydrocholesterol in LLC-bearing mice, particularly those fed the HFD, indicates an upregulated cholesterol synthesis. Cholesterol is essential for membrane biogenesis. Upregulation of cholesterol metabolism and sterol-dependent proliferation occur in mouse models of prostate cancer (37) and breast cancer metastasis (38) and in in vitro models of neoplastic cells $(37,39)$. In the current study, TRF lowered cholesterol, particularly dihydrocholesterol, in the plasma. It suggests that TRF may attenuate the LLC-mediated upregulation in cholesterol metabolism.

Moreover, higher levels of arachidonic acid in LLCbearing mice further support the notion of the upregulation in membrane biogenesis. Arachidonic acid is present in membrane phospholipids and is a precursor of eicosanoids, some of which may be carcinogenic $(40,41)$. Levels of linoleic acid, a precursor of arachidonic acid (20:4n-6), in TRF mice were higher than in their HFD-fed counterparts. However, the energy intake between these two groups is similar (11). Thus, it is likely that TRF may downregulate the pathway of linoleic acid utilization in LLC-bearing mice.

Lewis lung carcinoma-bearing mice, particularly those fed the HFD, exhibited elevated docosahexaenoic acid (22:6n-3; DHA) in the plasma. Docosahexaenoic acid competes against arachidonic acid for the active sites of enzymes that generate eicosanoids (42) and inhibits mammary tumorigenesis in rodent models $(43,44)$. Our finding suggests that the hosts may have developed self-defense against metastasis. However, it does not exclude the possibility that metastatic malignancy may similarly act against the host immune defense. It has been shown that DHA increases preneoplastic foci in the early stage of hepatic carcinogenesis in mice (45). The elevation in DHA may be through an increase in DHA synthesis from $\alpha$ linolenic acid (18:3n-3) provided by the dietary soybean oil that contains $7 \%$ of $\alpha$-linolenic acid (46). It is important to note that TRF, compared to the HFD, lowered DHA in plasma. Whether this TRF-mediated DHA reduction contributes to TRF mitigation of LLC metastasis warrants further investigation.

The current study showed that the HFD-fed mice had lower levels of non-esterified fatty acids (palmitoleic acid, myristic acid, and lauric acid) in the plasma. Decreases in non-esterified fatty acids are often observed in metabolomic analyses of cancer tissues from human patients $(47,48)$. The lack of differences between TRF and the HFD in the plasma non-esterified fatty acids suggests that TRF may not alter the disrupted fatty acid metabolism in LLC-bearing mice.

A limitation of this study is that we were not able to evaluate the changes in daily rhythm of metabolites by TRF in LLC-bearing mice, particularly the changes in metastases. Metabolism in cancer is disorganized and nutrient depriving, which directly disrupts the metabolic homeostasis of the host (12, 13). Findings from the current study warrant further investigation on TRF and the rhythmic changes in cancer metabolism and its impact to the host's metabolism.

The HFD is an experimentally created "environmental cue" that disrupts the daily eating/fasting pattern and leads 
to metabolic disturbance in laboratory rodents $(49,50)$. Time-restricted feeding restores the pattern by temporal regulation of food intake to a fixed time during the dark phase of the day. The most significant finding from the current study is that TRF shifts the metabolic profile of LLCbearing mice towards that of non-LLC-bearing controls. This shift, together with findings that TRF improves insulin sensitivity (11) and restores the daily rhythm of energy expenditure (6), indicates that TRF improves the metabolism of LLC-bearing mice. This improvement may have contributed to TRF mitigation of LLC metastasis.

\section{Conflicts of Interest}

The Authors have declared that no competing interests exist regarding this study.

\section{Authors' Contributions}

LY conceived and designed the study, performed the experiments, and collected data. LY, BR, and MP interpreted results and contributed to the preparation, review, and revision of the manuscript. All Authors agreed to be accountable for the content of the work.

\section{Acknowledgements}

The Authors gratefully acknowledge the assistance of the following staff of the Grand Forks Human Nutrition Research Center: Lana DeMars and Shawn Krueger for technical support and vivarium staff for preparing experimental diets and providing high-quality animal care.

\section{Funding}

This work was funded by the USDA Agricultural Research Service Projects \#3062-51000-050-00D, \#3062-51000-056-00D (LY), and \#3062-53000-001-00D (MP, BR).

\section{References}

1 Daniell HW: Increased lymph node metastases at mastectomy for breast cancer associated with host obesity, cigarette smoking, age, and large tumor size. Cancer 62: 429-435, 1988. PMID: 3383142. DOI: 10.1002/1097-0142(19880715)62:2<429::AIDCNCR2820620230>3.0.CO;2-4

2 Bassett WW, Cooperberg MR, Sadetsky N, Silva S, DuChane J, Pasta DJ, Chan JM, Anast JW, Carroll PR and Kane CJ: Impact of obesity on prostate cancer recurrence after radical prostatectomy: data from CaPSURE. Urology 66: 1060-1065, 2005. PMID: 16286124. DOI: 10.1016/j.urology.2005.05.040

3 Cowen S, McLaughlin SL, Hobbs G, Coad J, Martin KH, Olfert IM and Vona-Davis L: High-fat, high-calorie diet enhances mammary carcinogenesis and local inflammation in MMTVPyMT mouse model of breast cancer. Cancers (Basel) 7: 11251142, 2015. PMID: 26132316. DOI: 10.3390/cancers7030828
4 Kim EJ, Choi MR, Park H, Kim M, Hong JE, Lee JY, Chun HS, Lee KW and Yoon Park JH: Dietary fat increases solid tumor growth and metastasis of 4T1 murine mammary carcinoma cells and mortality in obesity-resistant BALB/c mice. Breast Cancer Res 13: R78, 2011. PMID: 21834963. DOI: 10.1186/bcr2927

5 Yan L and Sundaram S: Monocyte chemotactic protein-1 deficiency reduces spontaneous metastasis of Lewis lung carcinoma in mice fed a high-fat diet. Oncotarget 7: 2479224799, 2016. PMID: 27582541. DOI: 10.18632/oncotarget.8364

6 Sundaram S and Yan L: Time-restricted feeding reduces adiposity in mice fed a high-fat diet Nutr Res 36: 603-611, 2016. PMID: 27188906. DOI: 10.1016/j.nutres.2016.02.005

7 Hatori M, Vollmers C, Zarrinpar A, DiTacchio L, Bushong EA, Gill S, Leblanc M, Chaix A, Joens M, Fitzpatrick JA, Ellisman MH and Panda S: Time-restricted feeding without reducing caloric intake prevents metabolic diseases in mice fed a high-fat diet. Cell Metab 15: 848-860, 2012. PMID: 22608008. DOI: 10.1016/j.cmet.2012.04.019

8 Filipski E, Li XM and Levi F: Disruption of circadian coordination and malignant growth. Cancer Causes Control 17: 509-514, 2006. PMID: 16596304. DOI: 10.1007/s10552-0059007-4

9 Fu L, Pelicano H, Liu J, Huang P and Lee C: The circadian gene Period2 plays an important role in tumor suppression and DNA damage response in vivo. Cell 111: 41-50, 2002. PMID: 12372299.

10 Sundaram S and Yan L: Time-restricted feeding mitigates highfat diet-enhanced mammary tumorigenesis in MMTV-PyMT mice. Nutr Res 59: 72-79, 2018. PMID: 30442235. DOI: 10.1016/j.nutres.2018.07.014

11 Yan L, Sundaram S, Mehus AA and Picklo MJ: Time-restricted feeding attenuates high-fat diet-enhanced spontaneous metastasis of Lewis lung carcinoma in mice. Anticancer Res 39: 17391748, 2019. PMID: 30952713. DOI: 10.21873/anticanres.13280

12 Warburg O: On the origin of cancer cells. Science 123: 309-314, 1956. PMID: 13298683. DOI: 10.1126/science.123.3191.309

13 Rohm M, Zeigerer A, Machado J and Herzig S: Energy metabolism in cachexia. EMBO Rep 202019. PMID: 30890538. DOI: $10.15252 / \mathrm{embr} .201847258$

14 Sundaram S and Yan L: Dietary energy restriction reduces highfat diet-enhanced metastasis of Lewis lung carcinoma in mice. Oncotarget 7: 65669-65675, 2016. PMID: 27582541. DOI: 10.18632/oncotarget.11598

15 Reeves PG, Nielsen FH and Fahey GCJ: AIN-93 purified diets for laboratory rodents: final report of the American Institute of Nutrition Ad Hoc Writing Committee on the reformulation of the AIN-76A rodent diet. J Nutr 123: 1939-1951, 1993. PMID: 8229312. DOI: $10.1093 / \mathrm{jn} / 123.11 .1939$

16 Institute for Laboratory Animal Research: Guide for the care and use of laboratory animals. Washington, D.C.: National Academies Press, 2011.

17 Fiehn O, Garvey WT, Newman JW, Lok KH, Hoppel CL and Adams SH: Plasma metabolomic profiles reflective of glucose homeostasis in non-diabetic and type 2 diabetic obese AfricanAmerican women. PLoS One 5: e15234, 2010. PMID: 21170321. DOI: 10.1371/journal.pone.0015234

18 Piccolo BD, Keim NL, Fiehn O, Adams SH, Van Loan MD and Newman JW: Habitual physical activity and plasma metabolomic patterns distinguish individuals with low $v s$. high weight loss during controlled energy restriction. J Nutr 145: 681-690, 2015. PMID: 25833772. DOI: 10.3945/jn.114.201574 
19 Fiehn O, Wohlgemuth G and Scholz C: Setup and Annotation of Metabolomic Experiments by Integrating Biological and Mass Spectrometric Metadata. In: Data Integration in the Life Sciences. Ludäscher B and Raschid L (eds.). Berlin, Heidelberg: Springer, pp. 224-239, 2005.

$20 \mathrm{Xia} \mathrm{J}$ and Wishart DS: Using MetaboAnalyst 3.0 for Comprehensive Metabolomics Data Analysis. Curr Protoc Bioinformatics 55: 1410 11-14 10 91, 2016. PMID: 27603023. DOI: $10.1002 / \mathrm{cpbi} .11$

21 van den Berg RA, Hoefsloot HCJ, Westerhuis JA, Smilde AK and van der Werf MJ: Centering, scaling, and transformations: improving the biological information content of metabolomics data. BMC Genomics 7: 142, 2006. PMID: 16762068. DOI: 10.1186/1471-2164-7-142

22 Brodt P: Characterization of two highly metastatic variants of Lewis lung carcinoma with different organ specificities. Cancer Res 46: 2442-2448, 1986. PMID: 3697987.

23 Playdon MC, Ziegler RG, Sampson JN, Stolzenberg-Solomon R, Thompson HJ, Irwin ML, Mayne ST, Hoover RN and Moore SC: Nutritional metabolomics and breast cancer risk in a prospective study. Am J Clin Nutr 106: 637-649, 2017. PMID: 28659298.DOI: 10.3945/ajcn.116.150912

24 Yu W, Jia L, Wang P, Lawson KA, Simmons-Menchaca M, Park SK, Sun L, Sanders BG and Kline K: In vitro and in vivo evaluation of anticancer actions of natural and synthetic vitamin E forms. Mol Nutr Food Res 52: 447-456, 2008. PMID: 18381678. DOI: $10.1002 / \mathrm{mnfr} .200700254$

25 Fong MY, McDunn J and Kakar SS: Identification of metabolites in the normal ovary and their transformation in primary and metastatic ovarian cancer. PLoS One 6: e19963, 2011. PMID: 21625518. DOI: 10.1371/journal.pone.0019963

26 Traber MG: Vitamin E regulatory mechanisms. Annu Rev Nutr 27: 347-362, 2007. PMID: 17439363. DOI: 10.1146/annurev. nutr.27.061406.093819

27 Cheng Y, Yang X, Deng X, Zhang X, Li P, Tao J, Qin C, Wei J and Lu Q: Metabolomics in bladder cancer: a systematic review. Int J Clin Exp Med 8: 11052-11063, 2015. PMID: 26379905.

28 Mayers JR, Wu C, Clish CB, Kraft P, Torrence ME, Fiske BP, Yuan C, Bao Y, Townsend MK, Tworoger SS, Davidson SM, Papagiannakopoulos T, Yang A, Dayton TL, Ogino S, Stampfer MJ, Giovannucci EL, Qian ZR, Rubinson DA, Ma J, Sesso HD, Gaziano JM, Cochrane BB, Liu S, Wactawski-Wende J, Manson JE, Pollak MN, Kimmelman AC, Souza A, Pierce K, Wang TJ, Gerszten RE, Fuchs CS, Vander Heiden MG and Wolpin BM: Elevation of circulating branched-chain amino acids is an early event in human pancreatic adenocarcinoma development. Nat Med 20: 1193-1198, 2014. PMID: 25261994. DOI: $10.1038 / \mathrm{nm} .3686$

29 Guasch-Ferre M, Hruby A, Toledo E, Clish CB, MartinezGonzalez MA, Salas-Salvado J and Hu FB: Metabolomics in prediabetes and diabetes: A systematic review and meta-analysis. Diabetes Care 39: 833-846, 2016. PMID: 27208380. DOI: $10.2337 / \mathrm{dc} 15-2251$

30 Selvin E, Rynders GP and Steffes MW: Comparison of two assays for serum 1,5-anhydroglucitol. Clin Chim Acta 412: 793795, 2011. PMID: 21238440. DOI: 10.1016/j.cca.2011.01.007

31 Kumar N, Shahjaman M, Mollah MNH, Islam SMS and Hoque MA: Serum and plasma metabolomic biomarkers for lung cancer. Bioinformation 13: 202-208, 2017. PMID: 28729763. DOI: $10.6026 / 97320630013202$
32 Musharraf SG, Mazhar S, Choudhary MI, Rizi N and Atta ur R: Plasma metabolite profiling and chemometric analyses of lung cancer along with three controls through gas chromatographymass spectrometry. Sci Rep 5: 8607, 2015. PMID: 25712604. DOI: $10.1038 /$ srep08607

33 Dettmer K, Vogl FC, Ritter AP, Zhu W, Nurnberger N, Kreutz M, Oefner PJ, Gronwald W and Gottfried E: Distinct metabolic differences between various human cancer and primary cells. Electrophoresis 34: 2836-2847, 2013. PMID: 23857076. DOI: 10.1002/elps.201300228

34 Warburg O, Wind F and Negelein E: The metabolism of tumors in the body. J Gen Physiol 8: 519-530, 1927. PMID: 19872213. DOI: $10.1085 / j g p .8 .6 .519$

35 Miyauchi T, Uchida Y, Kadono K, Hirao H, Kawasoe J, Watanabe T, Ueda S, Okajima $\mathrm{H}$, Terajima $\mathrm{H}$ and Uemoto $\mathrm{S}$ : Up-regulation of FOXO1 and reduced inflammation by betahydroxybutyric acid are essential diet restriction benefits against liver injury. Proc Natl Acad Sci U S A 116: 13533-13542, 2019. PMID: 31196960 . DOI: 10.1073/pnas.1820282116

36 Lin AL, Zhang W, Gao X and Watts L: Caloric restriction increases ketone bodies metabolism and preserves blood flow in aging brain. Neurobiol Aging 36: 2296-2303, 2015. PMID: 25896951. DOI: 10.1016/j.neurobiolaging.2015.03.012

37 Zhuang L, Kim J, Adam RM, Solomon KR and Freeman MR: Cholesterol targeting alters lipid raft composition and cell survival in prostate cancer cells and xenografts. J Clin Invest 115: 959-968, 2005. PMID: 15776112. DOI: 10.1172/JCI19935

38 Johnson CH, Santidrian AF, LeBoeuf SE, Kurczy ME, Rattray NJW, Rattray Z, Warth B, Ritland M, Hoang LT, Loriot C, Higa J, Hansen JE, Felding BH and Siuzdak G: Metabolomics guided pathway analysis reveals link between cancer metastasis, cholesterol sulfate, and phospholipids. Cancer Metab 5: 9, 2017. PMID: 29093815. DOI: 10.1186/s40170-017-0171-2

39 Hirsch HA, Iliopoulos D, Joshi A, Zhang Y, Jaeger SA, Bulyk M, Tsichlis PN, Shirley Liu X and Struhl K: A transcriptional signature and common gene networks link cancer with lipid metabolism and diverse human diseases. Cancer Cell 17: 348361, 2010. PMID: 20385360. DOI: 10.1016/j.ccr.2010.01.022

40 Jones R, Adel-Alvarez LA, Alvarez OR, Broaddus R and Das S: Arachidonic acid and colorectal carcinogenesis. Mol Cell Biochem 253: 141-149, 2003. PMID: 14619964.

41 Yang P, Cartwright CA, Li J, Wen S, Prokhorova IN, Shureiqi I, Troncoso P, Navone NM, Newman RA and Kim J: Arachidonic acid metabolism in human prostate cancer. Int J Oncol 41: 14951503, 2012. PMID: 22895552. DOI: 10.3892/ijo.2012.1588

42 DiNicolantonio JJ, McCarty MF, Chatterjee S, Lavie CJ and O'Keefe JH: A higher dietary ratio of long-chain omega-3 to total omega- 6 fatty acids for prevention of COX-2-dependent adenocarcinomas. Nutr Cancer 66: 1279-1284, 2014. PMID: 25356937. DOI: 10.1080/01635581.2014.956262

43 Rose DP, Connolly JM and Coleman M: Effect of omega-3 fatty acids on the progression of metastases after the surgical excision of human breast cancer cell solid tumors growing in nude mice. Clin Cancer Res 2: 1751-1756, 1996.

44 Yuri T, Danbara N, Tsujita-Kyutoku M, Fukunaga K, Takada H, Inoue Y, Hada T and Tsubura A: Dietary docosahexaenoic acid suppresses $\mathrm{N}$-methyl- $\mathrm{N}$-nitrosourea-induced mammary carcinogenesis in rats more effectively than eicosapentaenoic acid. Nutr Cancer 45: 211-217, 2003. PMID: 12881016. DOI: $10.1207 / \mathrm{S} 1532$ 7914NC4502_11 
45 Pedersen KB, Pulliam CF, Patel A, Del Piero F, Watanabe TTN, Wankhade UD, Shankar K, Hicks C and Ronis MJ: Liver tumorigenesis is promoted by a high saturated fat diet specifically in male mice and is associated with hepatic expression of the proto-oncogene Agap2 and enrichment of the intestinal microbiome with Coprococcus. Carcinogenesis 40: 349-359, 2019. PMID: 30325408. DOI: 10.1093/carcin/bgy141

46 US National Nutrient Database: Soybean oil, salad or cooking, fat composition, 100g: United States Department of Agriculture, May 2016. Retrieved September 6, 2017.

47 Budczies J, Denkert C, Muller BM, Brockmoller SF, Klauschen F, Gyorffy B, Dietel M, Richter-Ehrenstein C, Marten U, Salek RM, Griffin JL, Hilvo M, Oresic M, Wohlgemuth G and Fiehn $\mathrm{O}$ : Remodeling of central metabolism in invasive breast cancer compared to normal breast tissue - a GC-TOFMS based metabolomics study. BMC Genomics 13: 334, 2012. PMID: 22823888. DOI: $10.1186 / 1471-2164-13-334$

48 Zhang G, He P, Tan H, Budhu A, Gaedcke J, Ghadimi BM, Ried T, Yfantis HG, Lee DH, Maitra A, Hanna N, Alexander HR and Hussain SP: Integration of metabolomics and transcriptomics revealed a fatty acid network exerting growth inhibitory effects in human pancreatic cancer. Clin Cancer Res 19: 4983-4993, 2013. PMID: 23918603. DOI: 10.1158/1078-0432.CCR-13-0209 49 Sherman H, Genzer Y, Cohen R, Chapnik N, Madar Z and Froy $\mathrm{O}$ : Timed high-fat diet resets circadian metabolism and prevents obesity. Faseb J 26: 3493-3502, 2012. PMID: 22593546.

50 Turek FW, Joshu C, Kohsaka A, Lin E, Ivanova G, McDearmon E, Laposky A, Losee-Olson S, Easton A, Jensen DR, Eckel RH, Takahashi JS and Bass J: Obesity and metabolic syndrome in circadian Clock mutant mice. Science 308: 1043-1045, 2005. PMID: 15845877. DOI: 10.1126/science. 1108750

Received February 11, 2020

Revised February 25, 2020

Accepted February 26, 2020 